\section{Mechanical obstruction to ventilation from an ovarian cyst during pregnancy}

Dicky Tay Hock Beng MBBS MMed(Anaes(h),

Low Tut Choon MBBS MMed(Anaesth)
This report documents the danger of the gravid uterus fixing a large ovarian cyst in a position disadvantageous 10 diaphrag. matic excursion and thereby obstructing ventilation. A 34-yearold pregnamt patient presented at 18 weeks amenorrhoea with a large ovarian cyst. She gave a history of exertional dyspnoea and orthopnoea. Clinical examination revealed a grossly enlarged abdomen and a respiratory rate of 28 breaths $\cdot \mathrm{min}^{-1}$. Intraoperatively, ventilation was markedly impaired resulting in cyanosis and bradycardia. This was relieved by drainage of the ovarian cyst. A left lateral tilt with manual traction on the tumour may have avoided this problem. Should the above measures be inadequate, immediate drainage of the cyst is essential. Severe respiratory distress may require ulirasoundguided, percutaneous, aspiration of the cyst preoperatively. However, as in this patient, the absence of gross signs of respiratory failure does not preclude acute ventilatory failure after induction of anaesthesia.

Il est possible qu' un utérus gravide refoule un gros kyste ovarien de façon à gêner le mouvement du diaphragme et faire obstacle à la ventilation. Une femme de 34 ans s'est présentée à sa dix-huitième semaine de grossesse avec une histoire de dyspnée à l' effort et d'orthopnée. A l'examen, son ventre était distendu par un kyste ovarien et elle respirait 28 fois par minute. Pendant l'opération, il érait difficile de la ventiler au point ou elle devint cyanosée el bradycarde. Le drainage diı kyste régla immédiatement le problème de ventilation. Nous aurions peut-être pu éviter ce problème en penchant la patiente vers la gauche et en tirant la tumeur vers le bas toutefois, advenant l'échec de celte mesure, un drainage immédiat du kyste s'impose. En présence

\section{Key words}

ANAESTHESIA: obstetrical; VENTILATION: obstruction, ovarian cyst.

From the Department of Anaesthesia, Alexandria Hospital, Singapore.

Address correspondence to: Dr. Dicky Tay HB, Department of Anaesthesia, Kandang Kerbau Hospital, Hampshire Road, Singapore 0821.

Accepted for publication 18th December, 1991. d' une détresse respiratoire préopératoire il vaudrait sans doute mieux faire un drainage transcutané du kyste avant l'opération cepentant, des symptômes moins marqués devrait quand même alerter l'anesthésiste.

Ovarian cysts complicating pregnancy pose a combination of surgical, obstetrical and anaesthetic problems. Pregnancy and ovarian cysts are seldom a problem to ventilation. However, their concurrence may result in ventilatory failure as illustrated by this case report.

\section{Case report}

A 34-yr-old pregnant patient (18 wk amenorrhoea) presented with a three-day history of exertional dyspnoea and orthopnoea. She had no history of chronic obstructive airway disease, cardiac disease or any other important medical history. Her abdomen was distended and her blood pressure $130 / 110 \mathrm{mmHg}$. She had a respiratory rate of 28 breaths $\cdot \mathrm{min}^{-1}$. There was no clinical evidence of respiratory disease or cardiac failure. An ultrasound investigation revealed the presence of a large ovarian cyst and urgent laparotomy was planned.

Prior to induction of anaesthesia, non-invasive BP monitoring and continuous ECG was commenced. The patient was comfortable and did not complain of orthopnoea when she was pre-oxygenated with $100 \%$ oxygen in the supine position. Intravenous access was established and $250 \mathrm{mg}$ thiopentone were administered. At loss of eyelash reflex, $75 \mathrm{mg}$ succinylcholine was administered, cricoid pressure applied and the trachea was intubated with an $8 \mathrm{~mm}$ oral tracheal tube when the patient was well relaxed. There was no difficulty with laryngoscopy and intubation. End-tidal capnography and auscultation confirmed the correct position of the tube. At this juncture it was noticed that the reservoir bag "felt a little tight." There were no rhonchi and breath sounds could be heard although they were somewhat harsh. It was concluded that the decrease in compliance was caused by the ovarian cyst which obstructed the excursion of the diaphragm. Surgery commenced and $30 \mathrm{mg}$ d-tubocurarine were administered and the lungs were ventilated with $33 \%$ 
oxygen and $67 \%$ nitrous oxide using an Air-Shield's ventimeter. It was then noticed that the bellows were not descending adequately. The lungs were then ventilated using the reservoir bag. Airway resistance was high and in spite of reaching airway pressures of $50 \mathrm{~cm} \mathrm{H}_{2} \mathrm{O}$ there was poor chest excursion. Air entry was poor and breath sounds were harsh. No rhonchi were heard.

Two possibilities were considered; an obstructed tracheal tube and severe bronchospasm. A suction catheter passed down the tracheal tube failed to descend further than the length of the tube. The trachea was immediately reintubated with a similar tube but ventilation did not improve. No defects were found in the removed tube. Halothane $0.5 \%$ was added in an attempt to relieve any bronchospasm but no improvement was noted and after about two minutes the halothane concentration was increased to 1\% whilst aminophylline was prepared. At this time it was noticed that the patient was becoming cyanosed. The lungs were ventilated with $100 \%$ oxygen and the surgeon was notified. Before aminophylline could be administered the ECG monitor revealed bigeniny and the heart rate had decreased from $120 \cdot \mathrm{min}^{-1}$ to $60 \cdot \mathrm{min}^{-1}$, with a systolic blood pressure of $142 \mathrm{mmHg}$. End-tidal carbon dioxide was then $55 \mathrm{mmHg}$.

By this time, the surgeon had exposed a left ovarian cyst with a diameter of $45 \mathrm{~cm}$ lying between the uterus and the diaphragm. The ovarian cyst appeared to be the cause of the respiratory obstruction. The cyst was drained and this resulted in immediate improvement in ventilation. Ten litres of serous fluid were removed in three minutes. The airway resistance returned to normal $\left(20 \mathrm{~cm} \mathrm{H}_{2} \mathrm{O}\right)$ and chest expansion improved. At this stage, the halothane vaporizer was turned off and use of $33 \%$ oxygen with $67 \%$ nitrous oxide resumed. Ventilation, patient colour, heart rate and rhythm returned to normal and a left oophorectomy and partial salpingectomy were performed. Neuromuscular blockade was reversed with $0.9 \mathrm{mg}$ atropine and $2.5 \mathrm{mg}$ neostigmine. Recovery was uneventful and there were no further respiratory difficulties.

\section{Discussion}

The anaesthetic, surgical and obstetric problems posed by an ovarian cyst during pregnancy depend upon how advanced the pregnancy is and the size of the ovarian cyst. Common surgical and obstetric problems include torsion of the pedicle, impaction of the tumour in the pelvis to cause retention of urine and obstruction of labour, malpresentation of the fetus, rupture of the cyst and finally malignant change.

Teratogenesis and spontaneous abortion are anaesthetic concerns in the first trimester. Later in pregnancy, aortocaval compression, miscarriage or premature la- bour, aspiration, difficult intubation and other more common problems complicating pregnancy often claim the attention of the anaesthetist. ${ }^{2}$ Hypotension may occur from aortocaval compression or from rapid relief of intra-abdominal pressure that has resulted in a chronically decreased splanchnic venous compliance.

Failure to recognize the possiblity of mechanical obstruction to ventilation led to a near fatal delay in the appropriate management of this patient. The ovarian cyst usually assumes a position behind the uterus or to its flank. In the supine position, the gravid uterus may force a large ovarian cyst into a position that may obstruct the excursion of the diaphragm. The possibility of mechanical obstruction to ventilation has received little emphasis in both anaesthetic and gynaecological textbooks.

Another less likely explanation for the obstruction to ventilation is that the cyst may have caused a tracheal shift such that the bevel of the endotracheal tube rested on the tracheal wall. It is, however, unlikely that the cyst could cause tracheal distortion due to the presence of rigid cartilaginous tracheal rings.

An obstructed endotracheal tube is a more common event. This could result from many causes such as secretions, herniation of the tracheal cuff or even from kinking of the endotracheal tube. ${ }^{3-8}$ However, in this instance the endotracheal tube was replaced and examined for defects. Also a suction catheter was able to descend the length of the tube.

Apart from a respiratory rate of 28 breaths $\cdot \mathrm{min}^{-1}$, the patient did not appear to be dyspnoeic, and was able to tolerate pre-oxygenation in the supine position. Mechanical obstruction to ventilation was therefore not anticipated. In retrospect, the history of orthopnoea in the absence of cardiac disease was ominous. Prior to surgery a left lateral tilt or a lateral uterine displacement device might have had a preventative role. Ultrasound-guided percutaneous drainage of the cyst would be indicated to relieve severe preoperative respiratory distress. In acute obstruction to ventilation, as in this patient, manual traction should be attempted. If this fails, surgical drainage must be performed expeditiously to restore ventilation.

In conclusion, mechanical obstruction to ventilation may occur when a large ovarian cyst complicates advanced pregnancy. This potentially fatal complication should be anticipated if respiratory distress is present preoperatively. Percutaneous drainage of the cyst may be required if there is severe preoperative ventilatory impairment. A left lateral tilt and manual traction on the abdominal mass may prevent the occurrence of sudden ventilatory obstruction after the induction of anaesthesia. Sudden and severe obstruction to ventilation that does not respond to these manoeuvres requires immediate surgical 
drainage. Any delay in diagnosis and intervention is potentially fatal.

\section{References}

1 Jeffcoate $N$. Principles of Gynaecology, $4 \mathrm{~h}$ ed. London and Boston: Butterworths 1974; 483-4.

2 Atkinson RS, Rushman GB, Lee JA. A Synopsis of Anaesthesia, 10th ed. Bristol: Wright 1987; 522-47.

3 Johnson JT, Maloney RW, Cummings CW. Tracheostomy tube: cuff obstruction. JAMA 1977; 211 .

4 Hartnet JS. Aberrant inflation of disposable endotracheal tube with complete airway obstruction. Journal of the American Association of Nurse Anesthetists 1970; 38: 57-8.

5 Stoneham FJR. Danger from cuffed endotracheal tubes. BMJ 1952; 2: 565 .

6 Seuffert $G W$, Urbach $K F$. An additional hazard of endotracheal intubation. Can Anaesth Soc J 1968; 15:300- 1 .

7 Pryer DL, Pryer RLR, Williams AF. Fatal respiratory obstruction due to faulty endotracheal tube. Lancet 1960; 2: 742-3.

8 Bernhard WN, Yost L, Turndorf H, Danziger $F$. Cuffed tracheal tubes - physical and behavioral characteristics. Anesth Analg 1982; 61: 36-41. 